\title{
Chile, el Pacto Social en Cuarentena
}

\author{
Boris Santander Cepeda \\ Universidad de Chile, Chile \\ bsantander@derecho.uchile.cl
}

\begin{abstract}
"Nunca, nunca, nunca jamás, experimentará otra vez esta maravillosa tierra, la opresión del hombre por el hombre. El sol jamás se pondrá para tan maravilloso logro humano. Que reine la libertad." (Nelson Mandela $\left.{ }^{I}\right)$
\end{abstract}

18 de Octubre de 2019. Chile, el chico bueno del barrio, el estudiante aventajado del neoliberalismo, que en 1990 transitó a la democracia con la Constitución de Pinochet, y la mantuvo hasta hoy, de súbito, sorpresivamente, al menos para la clase dirigente, se incendiaba. Literalmente.

Intentando apaciguar las protestas masivas, los partidos políticos con representación parlamentaria arribaron al "Acuerdo por la Paz y la Nueva Constitución, ${ }^{2}$ " que contempló un plebiscito para decidir si iniciar o no un proceso constituyente, que tendría lugar el 26 de abril de 2020. No obstante, la pandemia desatada por el virus Covid-19, derivó en la postergación del plebiscito para el 25 de octubre de 2020. Aquí se revisa este proceso y su "cuarentena".

\footnotetext{
${ }^{1}$ Mandela, Nelson. Discurso de investidura como Presidente de Sudáfrica. "El largo camino hacia la libertad", Ed. Aguilar,1995. p. 451.

${ }^{2}$ Disponible aquí:https://www.senado.cl/logran-historico-acuerdo-para-nueva-constitucion-participacion/ senado/2019-11-14/134609.html
} 


\section{Por el derecho de vivir en Paz}

Lo que comenzó como una protesta de secundarios por un alza marginal de la tarifa del tren subterráneo, se convertiría, en cuestión de días, en una protesta social masiva, que enarbolaba banderas antisistema, exigiendo el fin de pensiones, sanidad y educación superior basadas en el ahorro, el seguro y el endeudamiento individuales, un salario mínimo por sobre la línea de la pobreza, un trato equitativo para las mujeres y una nueva Constitución.

Subyaciendo a todas esas demandas, sintetizándolas pronto y superándolas después, se alzaba una, gritada y cantada, por el fin de los abusos de los poderosos y el reconocimiento de la igual dignidad de todos, en un nuevo pacto social.

En efecto, se hizo común que los manifestantes entonaran, como himnos, canciones populares representativas de esos anhelos, en particular, "El baile de los que sobran", del grupo de rock chileno de los '80, Los Prisioneros, ${ }^{3,4}$ y "El derecho de vivir en paz", del cantautor Víctor Jara, torturado y asesinado en los inicios de la dictadura de Pinochet, cuya letra fue adaptada para la ocasión, por un destacado elenco de artistas. ${ }^{5,6,7}$

Lamentablemente, como suele ocurrir, el lumpen violento y la brutalidad policial fueron condimentos que pronto se convirtieron en platos fuertes, con estaciones del tren subterráneo incendiadas, supermercados y tiendas saqueadas y barricadas por doquier, y represión de manifestantes con bombas lacrimógenas y disparos, y graves violaciones a los derechos humanos, entre las que destacaron

\footnotetext{
${ }^{3}$ Parte de su letra reza: "Nos dijeron cuando chicos, Jueguen a estudiar. Los hombres son hermanos y juntos deben trabajar. Oías los consejos. Los ojos en el profesor. Habia tanto sol sobre las cabezas. Y no fue tan verdad, porque esos juegos al final. Terminaron para otros con laureles y futuro. Y dejaron a mis amigos pateando piedras. Únanse al baile, de los que sobran. Nadie nos va a echar de más. Nadie nos quiso ayudar de verdad".

${ }^{4}$ Véase este video, grabado en la Plaza Italia, rebautizada por los manifestantes como Plaza de la Dignidad: https://www.youtube.com/watch?v=YklpiCIwB5g

${ }^{5}$ Parte de esta nueva letra, dice: "Con respeto y libertad. Un nuevo pacto social. Dignidad y educación. Que no haya desigualdad. La lucha es una explosión. Que funde todo el clamor. El derecho de vivir en paz."

${ }^{6}$ Aquí esta nueva versión: https://www.youtube.com/watch?v=wlfAf2AibA8

${ }^{7} \mathrm{Sin}$ duda, la protesta chilena ha sido potenciada las redes sociales, cuyo impacto muy bien ilustra RabinovichBerkman, Ricardo, “¿Cómo se hicieron los derechos humanos?”, Didot, 2013. Vol. I, p. 109 y ss.
}

\section{DERECHO GLOBAL. ESTUDIOS SOBRE DERECHO Y JUSTICIA}


lesiones oculares y agresiones sexuales, con toque de queda y militares en las calles de por medio, lo que no se veía desde la dictadura. ${ }^{8}$

Al respecto, el Instituto Nacional de Derechos Humanos reportó, al 13 de marzo de 2020, 1.234 víctimas de tortura y otros tratos crueles, inhumanos y degradantes, y 282 víctimas de tortura con violencia sexual. ${ }^{9}$

La situación llegó a tanto, que motivó tres acusaciones constitucionales, ${ }^{10}$ la primera en contra de un recién renunciado Ministro del Interior, Andrés Chadwick, la segunda en contra del propio Presidente, Sebastián Piñera, y la última en contra del Intendente de la Región Metropolitana, Felipe Guevara, aunque solo la primera fue finalmente aprobada, declarándose culpable al ex Ministro de vulnerar la Constitución, al permitir aquellas violaciones a los derechos humanos. ${ }^{11}$

Pese a ello, las protestas parecían no terminar. Tampoco las detuvieron los anuncios de reformas sociales, como el aumento de las pensiones básicas y el incremento del salario mínimo (subsidiado por el Estado), que fueron estimadas más bien menores.

En este contexto, a casi un mes del inicio de las protestas y con el explícito fin de apaciguar a la población, con fecha 15 de noviembre de 2019, la mayoría de los partidos políticos, en el seno del Congreso Nacional, suscribieron el "Acuerdo por la Paz y la Nueva Constitución".

\footnotetext{
${ }^{8}$ Por Decretos Supremos $N^{\circ} 472$ y N ${ }^{\circ} 479$, de Interior, de 19 y 20 de octubre de 2019, se declaró estado de excepción constitucional de emergencia, por 15 días, en la Región Metropolitana de Santiago. En: https://www. diariooficial.interior.gob.cl/publicaciones/2019/10/19/42481-B/01/1671764.pdf y https://www.diariooficial. interior.gob.cl/publicaciones/2019/10/20/42482-B/01/1671788.pdf

${ }^{9}$ Instituto Nacional de Derechos Humanos, Reporte del 13 de marzo de 2020, p.7. En https://www.indh.cl/bb/ wp-content/uploads/2020/04/Reporte-INDH-19-de-marzo-de-2020.pdf

${ }^{10}$ Impugnación de una alta autoridad, destinada a su destitución o inhabilitación, por graves infracciones a la Constitución y las leyes, que da origen a un juico jurídico - político sustanciado por el Congreso.

${ }^{11}$ Así lo informaba el Senado https://www.senado.cl/respaldan-acusacion-constitucional-contra-ex-ministrochadwick/senado/2019-12-11/105300.html
} 


\section{El Acuerdo por la Paz y la Nueva Constitución}

El Acuerdo contempló un plebiscito para resolver si iniciar o no un proceso constituyente y, en caso afirmativo, si llevarlo a cabo a través de una Convención Mixta Constitucional, con 172 integrantes, mitad electos al efecto y mitad parlamentarios, o a través de una Convención Constitucional, con 155 integrantes electos.

Es pertinente consignar que, actualmente, la Cámara de Diputados la componen, precisamente, 155 diputados (y el Senado, 50 senadores). ${ }^{12}$

Ahora bien, el plebiscito habrá de realizarse conforme a las normas electorales actualmente vigentes, entre ellas, el voto voluntario, aunque el referéndum posterior, ratificatorio de la Constitución que se proponga, se realizaría con voto obligatorio, según se acordó.

Luego, se estableció que, en su caso, el órgano constituyente "tendrá como único objeto redactar la nueva Constitución, no afectando competencias y atribuciones de los demás órganos y poderes del Estado y se disolverá una vez cumplida la tarea..." Enseguida, se resolvió que la Convención deberá aprobar las normas y el reglamento de votación por un quorum de dos tercios de sus miembros en ejercicio, no pudiendo alterar estas reglas. Estas limitaciones, según algunos, diferenciarían la Convención Constitucional de una Asamblea Constituyente. Como sea, la Convención dispondrá de un plazo de nueve meses, prorrogable por tres meses más, para culminar su labor.

Para materializar el Acuerdo, se definió la designación de una Comisión Técnica, que determinaría los aspectos indispensables. Días después, esa Comisión, que pasó a llamarse Mesa Técnica, quedó finalmente conformada por catorce expertos constitucionalistas, siete designados por el oficialismo y siete por la oposición, de los cuales cinco son mujeres, una del oficialismo y cuatro de la oposición.

La Mesa Técnica sesionó desde el 25 de noviembre, hasta el 6 de diciembre de $2019,{ }^{13}$ debatiendo sobre el procedimiento para definir la apertura y eventualmente

\footnotetext{
${ }^{12}$ Artículos 178 a 180 de la Ley $N^{\circ} 18.770$.

En https://www.leychile.cl/Navegar?idNorma=30082\&idParte=\&idVersion=

${ }^{13}$ Las sesiones, aquí:

https://www.bcn.cl/procesoconstituyente/detalle_cronograma?id=f_cronograma-2
} 
conducir un proceso constituyente, por medio de una Convención, así como sobre su conformación en base a paridad de género, participación de independientes y escaños reservados a pueblos indígenas, aspectos que no fueron acogidos.

Finalmente, ese 6 de diciembre de 2019, la Mesa Técnica propuso una reforma constitucional, ${ }^{14}$ que fue recogida en una serie de mociones parlamentarias que, refundidas, aprobase el Congreso, convirtiéndose en la Ley $\mathrm{N}^{\circ} 21.200$, de 24 de diciembre de 2019, que introdujo en la Constitución ${ }^{15}$ las normas que permiten la apertura del proceso constituyente, ${ }^{16}$ cuyo plebiscito fue fijado para el 26 de abril de 2020.

Ahora bien, las demandas sociales a las que se pretendía dar, en parte, respuesta, estaban cruzadas por las demandas feministas, con fuerte y creciente apoyo en la población, como lo evidenció el impacto, de alcance mundial, de la puesta en escena del colectivo teatral Las Tesis, con su cántico "Un violador en tu camino", estrenado en noviembre de 2019 en Valparaíso, puerto vecino a Santiago, en medio de las manifestaciones, y reproducido rápidamente por mujeres en Chile y en todo el mundo. ${ }^{17,18}$

Esto puede explicar que, para sorpresa de muchos, el 4 de marzo de 2020, y luego de bastante resistencia del oficialismo, el Congreso aprobase una reforma constitucional complementaria de aquella, que se convertiría en la Ley № 21.216, de 20 de marzo de 2020. ${ }^{19}$

Esta nueva ley introdujo las disposiciones transitorias $29^{\mathrm{a}}, 30^{\mathrm{a}}$ y $31^{\mathrm{a}}$ a la Constitución que, además de facilitar la presentación de candidaturas independientes a la Convención, obliga a que las listas de candidatos establezcan un orden de precedencia que inicie con una mujer, alternando luego entre los géneros y disponiendo realizar ajustes al resultado del proceso electoral, con

\footnotetext{
${ }^{14}$ La propuesta, aquí:

https://www.bcn.cl/obtienearchivo?id=documentos/10221.1/78180/1/Propuesta_reforma_constitucional_ mesa_tecnica.pdf

${ }^{15}$ El texto constitucional, aquí https://www.leychile.cl/Navegar?idNorma=242302

${ }^{16}$ En https://www.leychile.cl/Navegar?idNorma=1140340

${ }^{17}$ Parte de la letra dice: "El patriarcado es un juez, que nos juzga por nacer y nuestro castigo es la violencia que no ves. Es femicidio. Impunidad para mi asesino. Es la desaparición. Es la violación. Y la culpa no era mía, ni dónde estaba, ni cómo vestía..."

${ }^{18}$ Este video de la BBC, explica el fenómeno: https://www.youtube.com/watch?v=216SQqdn2Y8

${ }^{19}$ En https://www.leychile.cl/Navegar?idNorma=1143661
} 
eventuales desplazamientos de candidatos, de modo tal que el resultado final sea paritario. ${ }^{20}$

Con esto, Chile se convertiría en el primer país en contar con un órgano constituyente paritario.

\section{La Cuarentena}

La pandemia desatada por el Covid-19, que asola al mundo entero, sorprendió a Chile en medio de movilizaciones sociales que, se estimaba, aunque habían bajado su intensidad por desgaste, por rechazo a los elementos violentos y por la baja de actividad propia de los meses de verano, serían prontamente retomadas con fuerza.

Este aserto comprobó su veracidad con una multitudinaria marcha, el 8 de marzo de 2020, el Día Internacional de la Mujer, ${ }^{21}$ corroborando de paso, también, que las demandas feministas forman parte sustancial de los reclamos sociales.

No obstante, a poco andar, llegó el Covid-19, y para quedarse, al parecer, por un buen tiempo, por lo que el Gobierno decretó, el 18 de marzo de 2020, y por el lapso de 90 días, el estado de excepción constitucional de catástrofe, ${ }^{22}$ por calamidad pública, que le permite, entre otras cosas, restringir la libertad de tránsito, disponiendo la ya afamada cuarentena, esto es, el aislamiento de personas, en sus casas, por un tiempo determinado, para evitar el contagio.

No fue muy difícil consensuar, en este escenario, una nueva reforma constitucional, plasmada en la Ley $\mathrm{N}^{\circ} 21.221$, de 26 de marzo de $2020,{ }^{23}$ que estableció un nuevo itinerario electoral, fijando el plebiscito de eventual apertura del proceso constituyente para el 25 de octubre de $2020 .{ }^{24}$

\footnotetext{
${ }^{20}$ Estas reglas aplican solo a los Convencionales electos por la ciudadanía, no a los parlamentarios que integrarían la Convención Mixta.

${ }^{21}$ Los organizadoras cifraron la asistencia en dos millones de personas. Así lo informó CNN: https://www. cnnchile.com/8m/dia-mujer-coordinadora-8m-cifra-asistentes-marcha-carabineros_20200308/

${ }^{22}$ Decreto Supremo $\mathrm{N}^{\circ} 104$, de Interior. En https://www.leychile.cl/Navegar?idNorma=1143580\&idParte=0

${ }^{23}$ En https://www.leychile.cl/Navegar?idNorma=1143800\&idParte=10110794\&idVersion=2020-03-26

${ }^{24}$ Decreto Supremo No 388, de Interior, de 29 de marzo de 2020.
} 
Ahora bien, como han señalado Ferreyra y Quiroga, ${ }^{25,26}$ esta peste, en todo el mundo y, permítaseme, particularmente en Chile, no ha hecho más que acrecentar el estado de malestar ya instalado por la desigualdad y la precariedad de las mayorías, evidenciando la falta de infraestructura para la atención de la salud y hasta las serias dificultades para conseguir comida, que vivencian miles y miles, de cuya existencia parece que nos enteramos recién ahora, cuando gritan, hace un par de días, en Santiago, juntos, masivamente, pese al virus: ¡Hambre!, ${ }^{27}$ grito que se proyectara, multiplicándolo, en la icónica Torre Telefónica. ${ }^{28}$

Así las cosas, parece ser que las protestas sociales que motivaron el proceso constituyente, no se detendrán, sino solo momentáneamente, regresando, quizá con más fuerza, cuando se vaya el virus, y nos devuelva, sin duda, una sociedad más feble, más herida de desigualdad, al punto de la indignidad.

El proceso constituyente, entonces, será más necesario que ayer, pero menos suficiente aún, pues la sociedad exigirá, pronto, cambios reales, más allá del papel, en orden a incrementar, sustancialmente, los niveles de protección social y trato igualitario y digno.

\footnotetext{
En https://www.leychile.cl/Navegar?idNorma=1143840

${ }^{25}$ Ferreyra, Raúl Gustavo y Quiroga, María Gracia. El estado de malestar. Revista Derechos en Acción No 15 , junio 2020, Universidad Nacional de La Plata, ISSN 2525-1678.

${ }^{26}$ Ferreyra, Raúl Gustavo. El tiempo de la peste. Revista Derechos en Acción No 14, Verano 2019-2020, Universidad Nacional de La Plata, ISSN 2525-1678.

${ }^{27}$ Así lo informó la BBC, el 19 de mayo de 2020: https://www.bbc.com/mundo/noticias-america-latina-52717413 ${ }^{28}$ https://eluniversal.cl/contenido/12336/proyectan-la-palabra-hambre-en-edificio-telefonica-esto-en-protestacontra-las-m
}

Como citar el artículo: Santander, B. (2020). Derecho Comparado: Chile, el pacto social en cuarentena. Derecho Global, Estudios sobre Derecho y Justicia, V. (15) pp. 181-187 https://DOI.org/10.32870/dgedj.v5i15.377 